\title{
Cellular origin of bladder neoplasia and tissue dynamics of its progression to invasive carcinoma
}

\author{
Kunyoo Shin ${ }^{1,{ }^{*}}$, Agnes Lim $^{3}$, Justin I. Odegaard ${ }^{4}$, Jared D. Honeycutt ${ }^{6}$, Sally Kawano ${ }^{1}$, \\ Michael H. Hsieh ${ }^{5}$, and Philip A. Beachy ${ }^{1,2,3,7,{ }^{*}}$ \\ ${ }^{1}$ Institute for Stem Cell Biology and Regenerative Medicine, Stanford University School of \\ Medicine Stanford, CA 94305. \\ 2Department of Biochemistry, Stanford University School of Medicine Stanford, CA 94305. \\ ${ }^{3}$ Department of Developmental Biology, Stanford University School of Medicine Stanford, CA \\ 94305. \\ ${ }^{4}$ Department of Pathology, Stanford University School of Medicine Stanford, CA 94305. \\ ${ }^{5}$ Department of Urology, Stanford University School of Medicine Stanford, CA 94305. \\ ${ }^{6}$ Stanford Immunology, Stanford University School of Medicine Stanford, CA 94305. \\ ${ }^{7}$ Howard Hughes Medical Institute, Stanford University School of Medicine Stanford, CA 94305.
}

\section{Abstract}

Understanding how malignancies arise within normal tissues requires identification of the cancer cell of origin and knowledge of the cellular and tissue dynamics of tumor progression. Here we examine bladder cancer in a chemical carcinogenesis model that mimics muscle-invasive human bladder cancer. With no prior bias regarding genetic pathways or cell types, we prospectively mark or ablate cells to show that muscle-invasive bladder carcinomas arise exclusively from Sonic hedgehog (Shh)-expressing stem cells in basal urothelium. These carcinomas arise clonally from a single cell whose progeny aggressively colonize a major portion of the urothelium to generate a lesion with histological features identical to human carcinoma-in-situ. Shh-expressing basal cells within this precursor lesion become tumor-initiating cells, although $\boldsymbol{S h h}$ expression is lost in subsequent carcinomas. We thus find that invasive carcinoma is initiated from basal urothelial stem cells but that tumor cell phenotype can diverge significantly from that of the cancer cell-oforigin.

The idea that human malignancies may originate from adult tissue stem cells derives from the intrinsic ability of stem cells to self-renew, from their longevity and consequent ability to

Users may view, print, copy, and download text and data-mine the content in such documents, for the purposes of academic research, subject always to the full Conditions of use:http://www.nature.com/authors/editorial_policies/license.html\#terms

*Corresponding authors: Philip A. Beachy (pbeachy@stanford.edu) and Kunyoo Shin (kunyoos@stanford.edu). AUTHOR CONTRIBUTIONS

K.S. and P.A.B. conceived ideas and experimental design. K.S. and A.L. performed the experiments. J.I.O. performed the histopathological analysis, J.D.H. aided in orthotopic injection, S.K performed the genotyping of experimental mice, and M.H.H. helped analyze data. K.S. and P.A.B. wrote the manuscript. 
accrue multiple mutations, and from the phenotypic resemblance of tumor-propagating cells to tissue stem cells ${ }^{1-4}$. Experimental tests of this hypothesis, however, have revealed a surprising degree of complexity ${ }^{5}$. Recent mouse studies utilizing cell-specific genetic manipulation have produced evidence that ovarian cancer, glioblastoma, skin cancer, and intestinal adenomas/carcinomas are derived from tissue stem cells ${ }^{6-10}$, but other studies have suggested that lumenal epithelial cells may serve as the cancer cell-of-origin. Thus, in mouse mammary tissue, tumors of greatest histological similarity to human mammary adenocarcinoma arise upon Cre-mediated deletion of BRCA1/Tp53 in lumenal cells, even though aggressive human mammary tumors are phenotypically basal in character ${ }^{11,12}$. Similarly, with oncogene expression and transplantation into the murine kidney capsule as an assay, prostate adenocarcinoma arises exclusively from basal cells of mouse ${ }^{13,14}$ or human ${ }^{15}$ prostate whereas autochthonous adenocarcinomas caused by deletion of PTEN can arise from either basal or lumenal cells ${ }^{16,17}$, and the more aggressive cancers arise from lumenal cells. Several hematopoietic malignancies appear to arise not from stem but from progenitor cells, even when essential precursor genetic lesions are also present in the stem cells ${ }^{18}$. Finally, it is worth noting that many of these studies involve manipulation of a selected set of genetic pathways in a subset of cells of the target organ, which might reveal only a limited subset of the possible paths along which a malignancy may develop.

Carcinoma of the urinary bladder arises from the urothelium, a simple transitional epithelium lining the bladder lumen. This multi-layered epithelium consists of a lumenal layer of fully differentiated umbrella cells which overlie intermediate cells with limited proliferative potential, and a basal layer of $S h h$-expressing cells. The $S h h$-expressing cells can form and propagate bladder-like organoids from single cells in vitro, and when genetically marked in vivo can be shown to replenish all other urothelial cells following injury, a regenerative activity that persists through multiple rounds of injury over long periods of time ${ }^{19}$. These properties identify $S h h$-expressing basal cells as probable urothelial stem cells.

The pro-carcinogen N-butyl-N-4-hydroxybutyl nitrosamine (BBN) is specifically activated in bladder and induces aggressive muscle-invasive bladder carcinoma over time with little effect on other tissues ${ }^{20,21}$. Nitrosamines are potent mutagens present in cigarette smoke ${ }^{22}$, which is the most important known risk factor for human bladder cancer ${ }^{23,24}$. Here, using BBN carcinogenesis and genetic tools to mark or ablate cells, we demonstrate that Shhexpressing basal stem cells of the urothelium are the cell-of-origin for murine invasive urothelial carcinoma. Using multi-color cell marking and lineage tracing, we also show that precursor lesions during progression to invasive carcinoma arise from aggressive clonal expansion of single urothelial cells whose progeny colonize a major portion of the urothelium to generate a carcinoma-in-situ precursor lesion. Finally, although $S h h$ expressing cells within this lesion become tumor initiating cells, Shh expression is lost by the time carcinomas develop, demonstrating that the phenotypic properties of mature tumor cells can diverge from those of the cancer cell-of-origin. 


\section{RESULTS}

\section{Similarity of human and BBN-induced mouse bladder cancer}

We examined mouse bladder tissues after exposure to BBN in drinking water and noted that the histopathology of BBN-exposed bladders in our murine model evolves in a manner similar to human muscle-invasive carcinoma ${ }^{21,25}$. Bladder tissues thus appear normal, without cellular changes or tissue disorganization within the first two months of BBN exposure (Fig. 1a; Supplementary Table 1). Histologic abnormalities appeared at 3 months of BBN exposure, including areas of nuclear atypia, crowding, and architectural disarray histologically indistinguishable from human carcinoma in situ (CIS; Fig. 1b; Supplementary Table 1). At 4 months of BBN exposure, CIS became robust and widespread in most animals, with extensive urothelial thickening (Fig. 1b; Supplementary Table 1), and muscleinvasive carcinoma invariably developed by 6 months of BBN exposure (Fig. 1b;

Supplementary Fig. 1), with consequent illness and morbidity necessitating euthanasia by 8 months of BBN exposure. The urothelial thickening caused by BBN exposure is distinct from hyperplasia that is rapidly induced by bacterial or chemical injury ${ }^{19}$, as it requires months of BBN exposure to arise, does not recede, and is associated with CIS (Supplementary Fig. 2).

\section{CIS and invasive carcinoma develop from Shh-expressing basal stem cells}

The presence of basal cell character in tumor-propagating cells ${ }^{26,27}$, is consistent with our observation that the basal cell marker CK5 is expressed throughout BBN-induced tumors (see below). As other cancers with basal character derive from lumenal cells ${ }^{11,12}$, we examined the cancer cell of origin by prospective marking of basal urothelial stem cells. We injected $S h h^{\mathrm{CreER}}$; $R 26^{\mathrm{mTmG}}$ mice with tamoxifen (TM) to activate CreER and induce excision of $\mathrm{mT}$ (membrane-targeted tdTomato) and permanent marking of Shh-expressing basal cells and their progeny by expression of $\mathrm{mG}$ (membrane-targeted EGFP). TM treatment was followed by four- and six-month courses of exposure to BBN (Fig. 2 and Supplementary Fig. 3). We noted $\mathrm{mG}$ marking of both the CIS lesion at four months (5/5 mice) and invasive carcinomas at six months (6/6 mice) (Fig. 2a,b and Supplementary Fig. $3 a, b)$, indicating that both derive from $S h h$-expressing basal stem cells and that CIS may represent a precursor lesion in muscle-invasive carcinoma development, as widely believed in human patients ${ }^{25}$. Importantly, no unmarked invasive carcinomas were observed, despite the presence of many unmarked supra-basal and lumenal cells at the beginning of BBN exposure, suggesting that invasive carcinoma is exclusively derived from $S h h$-expressing basal stem cells.

\section{Ablation of basal stem cells abrogates BBN carcinogenesis}

We explicitly tested the requirement for basal stem cells in tumor formation by injecting TM into mice of the genotype $S h h^{\mathrm{CreER}}$; $R 26^{\mathrm{DTA}}$, in which expression of an attenuated form of the diphtheria toxin fragment A (DTA) ${ }^{28-30}$, results in highly efficient ablation of Shhexpressing basal cells and consequent loss of high levels of CK5 expression. The low levels of CK5 in remaining cells resemble those normally seen in intermediate cells (Fig. 3a), which do not express Shh. These mice failed to maintain normal bladder epithelial 
architecture (Fig. 3b) and died within 8-10 months, consistent with previous findings on urothelial turnover ${ }^{31}$ and the role of basal urothelial stem cells in bladder homeostasis ${ }^{19}$.

Upon exposure to BBN we found that vehicle-injected control mice developed invasive carcinoma marked by high-level expression of CK5 (7 of 7 mice, Fig. 3c; Supplementary Fig. 4), whereas TM-injected mice, in which basal stem cells were ablated, did not develop invasive carcinoma ( 0 of 7 mice, Fig. 3c), even when BBN exposure continued for 8 months (Supplementary Fig. 4). Basal stem cells thus are absolutely required for formation of BBNinduced tumors, and the more differentiated supra-basal and lumenal cells that remain in these TM-injected animals are not susceptible to BBN-induced carcinogenesis. The finding that $\mathrm{BBN}$-induced carcinomas are comprised entirely of the progeny of marked basal stem cells without contribution from unmarked intermediate or lumenal cells, together with the failure of BBN to induce tumors within animals lacking basal stem cells constitutes strong evidence that invasive bladder carcinoma originates exclusively from the $S h h$-expressing basal urothelial stem cell.

Although TM-injected $S h h^{\mathrm{CreER}}$; $R 26^{\mathrm{DTA}}$ animals exposed to BBN for six months displayed disrupted epithelial architecture (Fig. 3c), epithelial integrity was preserved after three or four months of BBN exposure, with only mild urothelial thickening (Fig. 3d). The residual levels of CK5 expression were similar to those of normal intermediate urothelial cells (Fig. 3a), suggesting that the limited urothelial thickening induced by BBN exposure may be supported by proliferation of intermediate cells. Progressive deterioration of urothelial integrity over longer periods of time in animals lacking basal stem cells, with or without carcinogen treatment, suggests the exhaustion of limited proliferative capacity of these intermediate cells.

To determine how loss of basal stem cells affects CIS during tumorigenesis of BBN-induced invasive cancer, histopathology of TM-injected $S h h^{\mathrm{CreER}} ; R 26^{\mathrm{DTA}}$ animals was evaluated at monthly intervals during BBN exposure. These animals developed CIS lesions to a significantly reduced extent (Fig. 4a,b; Supplementary Table 2,3). Epithelial architecture in basal cell-ablated bladders was maintained after three or four months of BBN exposure, with normal expression of the lumenal marker CK18 (Fig. 4c,d). The low frequency of CIS and absence of tumors at later stages of BBN exposure (Fig. 3c) in these mice thus are not due to gross disruption of urothelial architecture, and these results together strongly suggest that $S h h$-expressing basal cells are a cell of origin for invasive carcinomas and for precursor lesions during bladder tumorigenesis.

\section{Shh-positive cells in the intermediate lesion as a cell of origin of tumor-propagating cells}

To analyze the expression of Shh during tumor progression, $S h h^{\mathrm{CreER}} ; R 26^{\mathrm{mTmG}}$ mice were exposed to BBN for 4 months to generate CIS lesions, then injected with TM to label Shhexpressing cells a few days before sacrifice (Fig. 5a, upper left). We found that although all cells in CIS lesions of these mice expressed CK5 at a high level (Fig. 5a; Supplementary Fig. 5a), only a basal subset of these CK5-positive cells expressed $\mathrm{mG}$, indicating maintenance of Shh expression in a basal subpopulation of CK5-positive cells (Fig. 5a; Supplementary Fig. 5a). Other more lumenal progeny of these basal cells lack Shh expression but retain high levels of CK5. 
To investigate the cancer-forming capacities of these two CIS cell populations, $S h h^{\text {CreER} \text {; }}$ $R 26^{\mathrm{mTmG}}$ mice previously exposed to BBN for 4 months were injected with TM, thus marking $S h h$-positive cells in the basal layer, while the remaining cells retain expression of $\mathrm{mT}$. These mice were then subjected to further exposure to BBN for 2 months (Fig. 5b). These mice developed aggressive bladder cancers (Fig. 5c, left panel) comprising both $\mathrm{mG}$ positive and mT-positive cells (Fig. 5c, right panel), thus indicating that both Shh-positive and $S h h$-negative CIS cells contribute to invasive bladder cancers.

We established transplant models in which cells from primary BBN-induced bladder tumors were injected into immunocompromised mice to give rise to a secondary tumor, either orthotopically into the intramural portion of the bladder dome (Supplementary Fig. 5c) or subcutaneously into the flank. We then used these transplant models to test geneticallymarked cells from $S h h^{\mathrm{CreER}} ; R 26^{\mathrm{mTmG}}$ animals treated with TM at 4 months, followed by exposure to BBN for an additional two months as described above (Fig. 5b). EpCAM ${ }^{+}$cells (expressed in tumor cells, not in stroma) marked by expression of $\mathrm{mG}^{+}$or $\mathrm{mT}^{+}$were separated by fluorescence activated cell sorting (FACS; Supplementary Fig. 5b) and transplanted orthotopically at three dilutions to test their tumor-propagating abilities (Fig. $5 \mathrm{~d}$ ). We found that $\mathrm{mG}^{+}$cancer cells at all three dilutions were able to give rise to secondary tumors, whereas $\mathrm{mT}^{+}$cells did not (Fig. 5e; Supplementary Fig. 5d). Similar results were noted when cancer cells were separated by using only $\mathrm{mG}$ or $\mathrm{mT}$ expression in the subcutaneous model (Supplementary Fig. 6). We conclude that $S h h$-expressing cells in the CIS lesions generate the carcinoma cells that are capable of propagating the tumor in transplantation experiments.

\section{Absence of Shh expression in invasive carcinoma}

In our BBN murine model invasive carcinomas arise from $S h h$-expressing basal stem cells, with tumor development progressing through basal cells of the intermediate CIS lesion. As previous analyses revealed very low or undetectable expression of Shh mRNA in a group of human bladder carcinoma samples ${ }^{32}$, we further investigated Shh expression by inducing invasive carcinomas with six months of BBN exposure in $S h h^{\mathrm{CreER}} ; R 26^{\mathrm{mTmG}}$ mice, then injecting with TM a few days before sacrifice (Fig. 6a). We found that invasive carcinomas were entirely devoid of $\mathrm{mG}$ (Fig. 6b), which should provide a reliable indication of Shh expression ${ }^{19}$, despite continued strong expression of CK5. We further confirmed that expression of Shh is lost upon progression to invasive carcinoma by quantitative RT-PCR from material obtained by laser capture microdissection from BBN-induced bladder tumors (Fig. 6c, d and Supplementary Fig. 7). Thus, although Shh-expression marks the basal cellof-origin for invasive carcinomas and persists in the precursor lesion for these tumors, it is completely absent in the fully formed tumor. Our results with BBN-induced invasive bladder carcinoma mirror those reported for a set of human transitional cell carcinoma samples ${ }^{32}$, most of which were invasive ${ }^{33}$.

\section{Lineage and clonality in BBN-induced bladder carcinoma}

The development of recurrent, multifocal tumors is a common characteristic of human urothelial carcinoma, with some studies concluding that such tumors are clonally related, whereas others argue for distinct cellular origins ${ }^{34-43}$. To investigate lineage relationships 
and tissue dynamics in our model we used multi-color marking prior to BBN-induced

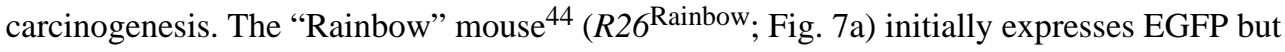
can recombine in a Cre-dependent fashion to express any of three additional distinct fluorescent proteins. Individual cells in the bladders of Actin ${ }^{\mathrm{CreER}} ; R 26^{\text {Rainbow }}$ mice treated with an appropriate level of TM thus are stochastically labeled in approximately equal numbers by permanent and heritable expression of one of four distinct fluorescent proteins (Fig. 7a,b; Supplementary Fig. 8). Upon exposure to BBN, these animals developed large CIS lesions marked by a single color and spanning extensive regions of contiguous cells (Fig. 7c, CIS \#1). The entire urothelium thus consists of the progeny of one (monoclonal) or at most a few cells (oligoclonal; Fig. 7c, CIS \#2).

Upon further BBN exposure we observed that invasive carcinomas appear to arise clonally, with a large tumor of a single color occupying the entire bladder (monoclonal; Fig. 7d) or with a few discrete tumor foci that are each labeled with a single color (oligoclonal; Fig. 7e). Oligoclonal tumors are usually accompanied by nearby CIS regions of the same color (Fig. 7e) and such clonally related CIS regions can be easily identified when the tumor is less advanced. Thus, at 5 months of BBN exposure we observed two distinctly marked CIS lesions together occupying the entire urothelium, with a small carcinoma beginning to develop entirely within one of these two distinctly marked CIS lesions (Fig. 7c, CIS \#2). Taken together, our observations suggest that CIS lesions develop clonally from one or a few cells with the remarkable ability to aggressively spread and displace other urothelial cells within major contiguous portions of the urothelium.

\section{DISCUSSION}

Nitrosamines are powerful mutagens found in cigarette smoke, which is the most important known risk factor for human bladder cancer ${ }^{22-24}$. Our use of the bladder-specific carcinogen BBN in the mouse thus mimics human bladder carcinogenesis in the type of carcinogen employed, in the lack of any prior bias regarding cell type or genetic pathway, and in carcinogen exposure over an extended period of time, thus permitting incremental progression and cell selection through genetic and tissue changes.

The prior identification of $S h$-expressing basal cells as urothelial stem cells was based in part on in vivo genetic marking ${ }^{19}$. Our use in this work of chemical carcinogenesis rather than genetic methods to induce urothelial carcinoma was a critical factor in permitting use of the same genetic methods to mark Shh-expressing basal stem cells and show that they give rise to invasive urothelial carcinomas. Our findings exclude other urothelial cells as the cellof-origin because: (i) marking of $S h h$-expressing basal cells exclusively generates marked tumors; and (ii) ablation of these cells renders the bladder incapable of generating a tumor. Although it is conceivable in (i) that tumors from supra-basal cells could be marked if basal cells generate other urothelial cell types during BBN exposure, we should also then see some unmarked tumors, as many unmarked supra-basal cells are also present in the urothelium at the time of BBN exposure. Furthermore, conversion of basal cells to suprabasal cells is a low frequency event, as we see very little proliferation and urothelial turnover within the first months of BBN exposure (Supplementary Fig. 2). Similarly, if tumors could arise from supra-basal cells, we would expect to see tumors arising in (ii), 
where Shh-expressing cells are ablated in a urothelium that appears normal with respect to its basic architecture and the presence of intermediate cells and well-differentiated umbrella cells. The fundamental integrity of the urothelium in these animals is suggested by their survival for at least 8 months after the ablation of stem cells, and is consistent with the previous assessment of a 10-month turnover time for murine urothelium ${ }^{31}$. The exclusive presence of marked tumors in $(i)$ and the absence of tumors in (ii) together constitute strong positive and negative evidence that clearly identifies the $S h h$-expressing basal urothelial stem cell as the exclusive cell of origin in invasive bladder carcinoma.

As recently demonstrated, tumor-propagating cells isolated from human bladder carcinomas have basal character ${ }^{26,27}$, and thus resemble the basal cell of origin identified here. This relationship, however, is distinct from that in tumors such as mammary adenocarcinoma, in which a tumor with basal character arises from a lumenal cell of origin ${ }^{11,12}$, or prostate adenocarcinoma, which has lumenal character but evidently can originate from lumenal or basal cells ${ }^{13-17}$. In addition, despite the apparent basal character of tumor-propagating cells of bladder carcinoma, most human invasive bladder carcinomas and the invasive carcinoma cells of our murine model differ strikingly from their cells of origin in having lost expression of $S h$.

In human bladder carcinogenesis, CIS is widely thought of as a precursor to invasive carcinoma ${ }^{25}$. Such lesions have long been thought of as stages in the development of other cancers, as well. For example, prostatic intraepithelial neoplasia (PIN) in prostate adenocarcinoma ${ }^{45,46}$, pancreatic intraepithelial neoplasia (PanIN) in pancreatic adenocarcinoma ${ }^{47,48}$, mammary ductal carcinoma in situ (DCIS $)^{49}$, and adenomatous polyps of the colon ${ }^{50}$ are commonly discussed as intermediate stages of cancer progression, and these lesions often carry genetic alterations similar to those of fully developed carcinomas. Conclusive evidence tracing the origin of malignancy directly to such precursor lesions, however, has largely been lacking. The tools of lineage tracing applied here in the murine BBN model allow us to definitively address the relationship of intermediate lesions to invasive carcinoma, and we have been able to confirm not only that CIS is within the lineage leading to invasive carcinoma, but also to identify basal $S h h$-expressing cells within the CIS lesion as the cells that acquire tumor-propagating ability upon formation of an invasive carcinoma.

One of the most striking findings to emerge from our multi-color lineage studies in the BBN model is the remarkable ability of a single urothelial cell to sweep through and displace all other cells within a large contiguous portion of the urothelium. This finding is likely relevant to the extensive literature on clonal relationships among synchronous or metachronous human bladder tumors ${ }^{34-43}$. The tools that previously have been used to determine clonal relationships include X-inactivation analysis, comparative genome hybridization (CGH), loss of heterozygosity analyses, and mutational analysis to compare chromosomal and genetic alterations in different tumors. The conclusions of these studies vary, and it has been proposed that multifocal tumors with a monoclonal origin may have divergent late genetic changes whose analysis could lead to the erroneous conclusion that they are multiclonal ${ }^{51,52}$. The uncertainty in interpreting these types of results thus arises in part from uncertainty regarding the sequence of genetic events within tumors that are used as the basis 
for analysis. Our multi-color marking experiments in the BBN model use distinctive marks generated prior to carcinogenesis and thus remove all ambiguity with regard to sequence. Our observation that a single marked cell under mutagenic pressure can aggressively proliferate and spread through extensive contiguous regions of the urothelium provides a clear basis for the clonal relationships identified among multifocal tumors within a single bladder ${ }^{34-38}$. This aggressive intraepithelial expansion of a single clone and our observations of invasive tumors surrounded by non-invasive regions of clonally related CIS urothelium also provide a correlate for the commonly reported occurrence of a tumor surrounded by a region of abnormal but benign epithelium ${ }^{53-55}$. Finally, the occurrence of two or three unrelated CIS lesions or tumors within a single bladder illustrates the possibility of generating multifocal tumors of distinct clonal origin; the probability of this occurrence may depend on the degree of mutagenic pressure.

The events of carcinoma initiation and progression are summarized in Fig. 8, and begin with accumulation of mutations in Shh-expressing urothelial basal stem cells, the cancer cell of origin. These mutations allow the progeny of a single cell to sweep through and colonize an extensive portion of the urothelium and form a CIS precursor lesion. Within this lesion, Shhpositive basal cells accumulate further mutations, leading to further clonal expansion and ultimately to transformation and invasion of the stromal and muscle layers of the bladder. The latter stages of this process are consistently accompanied by loss or attenuation of Shh expression, and further studies will be required to establish the significance of this loss. One of the key features of our findings is that progression to invasion occurs in the context of a precursor lesion with pre-neoplastic changes that aggressively spreads through most if not all of the urothelium. Resection of invasive carcinomas, even if complete, thus may leave in place urothelial cells that already have taken several early steps along the path to invasive tumor formation, thus potentially accounting for the frequent recurrence and high morbidity of invasive human bladder cancer.

\section{METHODS}

\section{Mice}

For lineage tracing experiments, $S h h^{\mathrm{CreER} / \mathrm{WT}}$ mice were mated with the $R 26^{\mathrm{mTmG} / \mathrm{mTmG}}$ strain to obtain $S h h^{\mathrm{CreER} / \mathrm{WT}} ; R 26^{\mathrm{mTmG} / \mathrm{WT}}$ mice. For cell ablation experiments, $S h h^{\mathrm{CreER} / \mathrm{WT}}$ mice were mated with $R 26^{\mathrm{DTA} / \mathrm{WT}}$ strain to obtain $S h h^{\mathrm{CreER} / \mathrm{WT}} ; R 26^{\mathrm{DTA} / \mathrm{WT}}$ mice. For cancer clonality studies, TM-activated Cre combined with the $R 26^{\text {Rainbow/WT }}$ were used to mark cells and their progeny with one of four fluorescence colors. All mouse strains except for Rainbow mice were obtained from Jackson Laboratories. Male mice at 8-10 weeks of age at the beginning of BBN treatment were utilized. For each experiment, no statistical method was used to predetermine sample size, and mice in each cage were randomly selected for drug/tamoxifen or control treatments. The investigators were blinded to allocation during experiments and outcome assessment. Histological assessment of bladder tissue sections was blinded in order to ensure that the pathologist who assessed the tissues did not know which treatment group each sample belonged to. Mouse procedures were performed under isoflurane anesthesia, which was administered in a fume hood with a standard vaporizer (J.B. Baulch \& Associates). All procedures were performed under a 
protocol approved by the Administrative Panel on Laboratory Animal Care at Stanford University.

\section{BBN-induced bladder carcinogenesis}

A $0.1 \%$ concentration of BBN (TCI America) was dissolved in drinking water, and BBNcontaining water was provided to mice ad libitum for 4-6 months in a dark bottle. BBNcontaining water was changed twice a week. Bladders were collected and analyzed after 4 to 6 months of BBN administration.

\section{Lineage tracing studies}

For lineage marking of Shh expressing basal cells prior to BBN exposure, $S h h^{\mathrm{CreER} / \mathrm{WT}}$; $R 26^{\mathrm{mTmG} / \mathrm{WT}}$ mouse strains were injected intraperitoneally with $4 \mathrm{mg}$ of TM per $30 \mathrm{~g}$ body weight daily for three consecutive days. BBN-containing water was provided to mice ad libitum for 4 or 6 months beginning five days after the last TM injection. Mice were sacrificed and bladders dissected for further analysis. For marking and tracing of Shhexpressing hyperplastic cells, $S h h^{\mathrm{CreER} / \mathrm{WT}} ; R 26^{\mathrm{mTmG} / \mathrm{WT}}$ mice were exposed to BBN for 4 months and then injected intraperitoneally with $4 \mathrm{mg}$ of TM (per 30g body weight) daily for three consecutive days. Mice were then provided with BBN-containing water for an additional 2 months, sacrificed, and bladders dissected for further analysis. To label Shh expressing cells in invasive carcinoma, $S h h^{\mathrm{CreER} / \mathrm{WT}} ; R 26^{\mathrm{mTmG} / \mathrm{WT}}$ mouse strains were provided with BBN-containing water for 6 months and then injected intraperitoneally with $4 \mathrm{mg}$ of TM (per 30g body weight) daily for three consecutive days. Mice were sacrificed five days after the last TM injection, and bladders were analyzed. To label Shh expressing cells in CIS lesions, $S h h^{\mathrm{CreER} / \mathrm{WT}} ; R 26^{\mathrm{mTmG} / \mathrm{WT}}$ mouse strains were provided with $\mathrm{BBN}$ containing water for 4 months and then injected intraperitoneally with $4 \mathrm{mg}$ of TM (per $30 \mathrm{~g}$ body weight) daily for three consecutive days before mice were sacrificed. For cancer clonality studies, Actin ${ }^{\mathrm{CrEER} / \mathrm{WT}} ;$ R26 $6^{\mathrm{RAIBOW} / \mathrm{WT}}$ mouse strains were injected with $2 \mathrm{mg}$ of TM (per 30g body weight) prior to BBN exposure.

\section{Cell ablation studies}

For ablation of Shh expressing cells prior to BBN exposure, $S h h^{\mathrm{CreER} / \mathrm{WT}} ; R 26^{\mathrm{DTA} / \mathrm{WT}}$ mice were injected intraperitoneally with $4 \mathrm{mg}$ of TM (per 30g body weight) daily for five consecutive days. Bladders then were examined for ablation of basal cells five days after the last TM injection. For studies on the effect of basal cell loss on bladder tumorigenesis, BBNcontaining water was provided to mice ad libitum for 4 to 6 months after basal cell ablation by daily TM injection for five days as described above. Mice were then sacrificed and bladders then dissected for further analysis.

\section{Immunofluorescence analysis}

Bladders were dissected and embedded in OCT compound for snap freezing (Tissue-Tek). Frozen blocks were sectioned at $10 \mathrm{~mm}$ intervals using a Microm cryostat. For immunostaining, frozen tissue sections were fixed in $4 \%$ paraformaldehyde for 30min at $4{ }^{\circ} \mathrm{C}$. After washing three times with PBS, tissue sections were blocked in $2 \%$ goat serum in PBS containing $0.25 \%$ Trion X-100 for $1 \mathrm{hr}$, and incubated with primary antibodies diluted 
in blocking solution overnight at $4^{\circ} \mathrm{C}$ in a humidified chamber (Rabbit anti-CK5, 1:300 dilution, ab53121 from Abcam; Rat anti-CK18/8, 1:300 dilution, Troma-I from hybridoma bank, Rabbit anti-GFP, 1:1000 dilution, A-11122 from Invitrogen). Sections were washed three times with PBS containing $0.25 \%$ Triton X-100, incubated with DAPI and appropriate Alexa fluor 488, 594, or 633 conjugated secondary antibodies diluted 1:1000 in blocking solution for $2 \mathrm{hr}$ at RT, washed again three times, and mounted on slides with Prolong Gold mounting reagent (Invitrogen). All images were obtained using a Zeiss LSM 510 inverted confocal microscope and prepared for publication with Zeiss LSM 5 Image Browser software and Adobe Photoshop CS3.

\section{Laser capture microdissection}

For laser capture microdissection (LCM), bladder sections were prepared using an LCM staining kit (Ambion) and a Leica LMD6000 Laser Microdissection Microscope. After LCM, total RNA was prepared using RNAqueous-Micro RNA isolation kit (Ambion). Quantitative RT-PCR was performed using iScript one step RT-PCR kit with SYBR Green and the Bio-Rad iCycler (BioRad). All values normalized to the HPRT internal control.

\section{Tumor transplantation}

Bladder tumors were minced, and then incubated with Liberase blendzymes 2 and 4 (Roche) in DMEM (Invitrogen) at $37^{\circ} \mathrm{C}$ for $3 \mathrm{~h}$. A single cell suspension was obtained by $10 \mathrm{~min}$ of trituration every 30min during this incubation, followed by filtration through $70 \mu \mathrm{m}$ cell strainers. After the lysis of red blood cells, cells were washed with HBSS/2\% fetal bovine serum and were counted using a hemocytometer (Hausser Scientific). Cells were resuspended in $100 \mu \mathrm{l}$ HBSS containing 30\% Matrigel (BD Bioscience) and then injected with 31-gauge insulin syringes (Becton Dickinson) subcutaneously into the flanks of anesthetized NSG mice (Jackson Laboratories). For the transplantation of genetically labelled cells, $S h h^{\mathrm{CreER} / \mathrm{WT}} ; R 26^{\mathrm{mTmG} / \mathrm{WT}}$ mice were exposed to BBN for 4 months and then injected intraperitoneally with $4 \mathrm{mg}$ of TM per $30 \mathrm{~g}$ body weight daily for three consecutive days. Mice were provided with BBN-containing water for an additional 2 months. Bladder tumors from resulting mice were dissociated as described above. Cells were sorted using a FACS Ariall cytometer (BD Biosciences), and analysis of flow cytometry data was performed using FlowJo Software (Treestar). FACS-sorted mG-positive and mT-positive cancer cells were separately injected into NSG mice as described above. For the transplantation of mixed cells, FACS-sorted mG-positive and mT-positive cancer cells were mixed in $100 \mu \mathrm{l} \mathrm{HBSS}$ containing 30\% Matrigel (BD Bioscience). The mixed cell suspension was injected into NSG mice as described above. For orthotopic model, mG/ EpCAM- and mT/EpCAM- positive cells were FACS-sorted and injected submucosally into the anterior aspect of the bladder dome. Abdominal incisions were then closed with 4-0 Vicryl suture, and the surgical site was treated once with topical antibiotic ointment.

\section{Supplementary Material}

Refer to Web version on PubMed Central for supplementary material. 


\section{ACKNOWLEDGMENTS}

We thank I. Weissman and Y. Rinkevich for their generous provision of the "Rainbow" mouse, T. Desai, A. Oro, J. Sage for their critical reading of the manuscript, and the Stanford Neuroscience Microscopy Service for help with confocal microscopy. This research was supported in part by grants from the National Institutes of Health (P.A.B) and a Pathway to Independence Award (K99/R00) to K.S. P.A.B. is an investigator of the Howard Hughes Medical Institute.

\section{REFERENCES}

1. Reya T, Morrison SJ, Clarke MF, Weissman IL. Stem cells, cancer, and cancer stem cells. Nature. 2001; 414:105-111. [PubMed: 11689955]

2. Taipale J, Beachy PA. The Hedgehog and Wnt signalling pathways in cancer. Nature. 2001; 411:349-354. [PubMed: 11357142]

3. Bonnet D, Dick JE. Human acute myeloid leukemia is organized as a hierarchy that originates from a primitive hematopoietic cell. Nature medicine. 1997; 3:730-737.

4. Al-Hajj M, Wicha MS, Benito-Hernandez A, Morrison SJ, Clarke MF. Prospective identification of tumorigenic breast cancer cells. Proceedings of the National Academy of Sciences of the United States of America. 2003; 100:3983-3988. [PubMed: 12629218]

5. Blanpain C. Tracing the cellular origin of cancer. Nature cell biology. 2013; 15:126-134. [PubMed: 23334500]

6. Barker N, et al. Crypt stem cells as the cells-of-origin of intestinal cancer. Nature. 2009; 457:608611. [PubMed: 19092804]

7. Schepers AG, et al. Lineage tracing reveals Lgr5+ stem cell activity in mouse intestinal adenomas. Science. 2012; 337:730-735. [PubMed: 22855427]

8. Flesken-Nikitin A, et al. Ovarian surface epithelium at the junction area contains a cancer-prone stem cell niche. Nature. 2013; 495:241-245. [PubMed: 23467088]

9. Chen J, et al. A restricted cell population propagates glioblastoma growth after chemotherapy. Nature. 2012; 488:522-526. [PubMed: 22854781]

10. Driessens G, Beck B, Caauwe A, Simons BD, Blanpain C. Defining the mode of tumour growth by clonal analysis. Nature. 2012; 488:527-530. [PubMed: 22854777]

11. Molyneux G, et al. BRCA1 basal-like breast cancers originate from luminal epithelial progenitors and not from basal stem cells. Cell Stem Cell. 2010; 7:403-417. [PubMed: 20804975]

12. Lim E, et al. Aberrant luminal progenitors as the candidate target population for basal tumor development in BRCA1 mutation carriers. Nature medicine. 2009; 15:907-913.

13. Lawson DA, et al. Basal epithelial stem cells are efficient targets for prostate cancer initiation. Proceedings of the National Academy of Sciences of the United States of America. 2010; 107:2610-2615. [PubMed: 20133806]

14. Mulholland DJ, et al. Lin-Sca-1+CD49fhigh stem/progenitors are tumor-initiating cells in the Ptennull prostate cancer model. Cancer research. 2009; 69:8555-8562. [PubMed: 19887604]

15. Goldstein AS, Huang J, Guo C, Garraway IP, Witte ON. Identification of a cell of origin for human prostate cancer. Science. 2010; 329:568-571. [PubMed: 20671189]

16. Wang X, et al. A luminal epithelial stem cell that is a cell of origin for prostate cancer. Nature. 2009; 461:495-500. [PubMed: 19741607]

17. Wang ZA, et al. Lineage analysis of basal epithelial cells reveals their unexpected plasticity and supports a cell-of-origin model for prostate cancer heterogeneity. Nature cell biology. 2013; 15:274-283. [PubMed: 23434823]

18. Miyamoto T, Weissman IL, Akashi K. AML1/ETO-expressing nonleukemic stem cells in acute myelogenous leukemia with 8;21 chromosomal translocation. Proceedings of the National Academy of Sciences of the United States of America. 2000; 97:7521-7526. [PubMed: 10861016]

19. Shin K, et al. Hedgehog/Wnt feedback supports regenerative proliferation of epithelial stem cells in bladder. Nature. 2011; 472:110-114. [PubMed: 21389986] 
20. Nagao M, Suzuki E, Yasuo K, Yahagi T, Seino Y. Mutagenicity of N-butyl-N-(4hydroxybutyl)nitrosamine, a bladder carcinogen, and related compounds. Cancer Res. 1977; 37:399-407. [PubMed: 318920]

21. Bryan GT. The pathogenesis of experimental bladder cancer. Cancer research. 1977; 37:28132816. [PubMed: 326392]

22. Hecht SS. Cigarette smoking: cancer risks, carcinogens, and mechanisms. Langenbecks Arch Surg. 2006; 391:603-613. [PubMed: 17031696]

23. Zeegers MP, Tan FE, Dorant E, van Den Brandt PA. The impact of characteristics of cigarette smoking on urinary tract cancer risk: a meta-analysis of epidemiologic studies. Cancer. 2000; 89:630-639. [PubMed: 10931463]

24. Bryan GT. Pathogenesis of human urinary bladder cancer. Environmental health perspectives. 1983; 49:201-207. [PubMed: 6832092]

25. Spruck CH 3rd, et al. Two molecular pathways to transitional cell carcinoma of the bladder. Cancer research. 1994; 54:784-788. [PubMed: 8306342]

26. Chan KS, et al. Identification, molecular characterization, clinical prognosis, and therapeutic targeting of human bladder tumor-initiating cells. Proc Natl Acad Sci U S A. 2009; 106:1401614021. [PubMed: 19666525]

27. He X, et al. Differentiation of a highly tumorigenic basal cell compartment in urothelial carcinoma. Stem Cells. 2009; 27:1487-1495. [PubMed: 19544456]

28. Yamaizumi M, Mekada E, Uchida T, Okada Y. One molecule of diphtheria toxin fragment A introduced into a cell can kill the cell. Cell. 1978; 15:245-250. [PubMed: 699044]

29. Maxwell F, Maxwell IH, Glode LM. Cloning, sequence determination, and expression in transfected cells of the coding sequence for the tox 176 attenuated diphtheria toxin A chain. Molecular and cellular biology. 1987; 7:1576-1579. [PubMed: 3110596]

30. Wu S, Wu Y, Capecchi MR. Motoneurons and oligodendrocytes are sequentially generated from neural stem cells but do not appear to share common lineage-restricted progenitors in vivo. Development. 2006; 133:581-590. [PubMed: 16407399]

31. Jost SP. Cell cycle of normal bladder urothelium in developing and adult mice. Virchows Arch B Cell Pathol Incl Mol Pathol. 1989; 57:27-36. [PubMed: 2567547]

32. Thievessen I, Wolter M, Prior A, Seifert HH, Schulz WA. Hedgehog signaling in normal urothelial cells and in urothelial carcinoma cell lines. J Cell Physiol. 2005; 203:372-377. [PubMed: 15521068]

33. Kimura F, et al. Decrease of DNA methyltransferase 1 expression relative to cell proliferation in transitional cell carcinoma. International journal of cancer. Journal international du cancer. 2003; 104:568-578. [PubMed: 12594811]

34. Sidransky D, et al. Clonal origin bladder cancer. The New England journal of medicine. 1992; 326:737-740. [PubMed: 1445507]

35. Simon R, et al. Cytogenetic analysis of multifocal bladder cancer supports a monoclonal origin and intraepithelial spread of tumor cells. Cancer research. 2001; 61:355-362. [PubMed: 11196186]

36. Fadl-Elmula I, et al. Cytogenetic monoclonality in multifocal uroepithelial carcinomas: evidence of intraluminal tumour seeding. British journal of cancer. 1999; 81:6-12. [PubMed: 10487605]

37. Yamamoto S, Tatematsu M, Yamamoto M, Fukami H, Fukushima S. Clonal analysis of urothelial carcinomas in $\mathrm{C} 3 \mathrm{H} / \mathrm{HeN}<-->\mathrm{BALB} / \mathrm{c}$ chimeric mice treated with $\mathrm{N}$-butyl-N-(4hydroxybutyl)nitrosamine. Carcinogenesis. 1998; 19:855-860. [PubMed: 9635874]

38. Hafner C, et al. Evidence for oligoclonality and tumor spread by intraluminal seeding in multifocal urothelial carcinomas of the upper and lower urinary tract. Oncogene. 2001; 20:4910-4915. [PubMed: 11521204]

39. Trkova M, et al. Analysis of genetic events in 17p13 and 9p21 regions supports predominant monoclonal origin of multifocal and recurrent bladder cancer. Cancer letters. 2006; 242:68-76. [PubMed: 16343743]

40. Duggan BJ, et al. Oligoclonality in bladder cancer: the implication for molecular therapies. J Urol. 2004; 171:419-425. [PubMed: 14665946] 
41. Dahse R, Gartner D, Werner W, Schubert J, Junker K. P53 mutations as an identification marker for the clonal origin of bladder tumors and its recurrences. Oncology reports. 2003; 10:2033-2037. [PubMed: 14534739]

42. Paiss T, et al. Some tumors of the bladder are polyclonal in origin. J Urol. 2002; 167:718-723. [PubMed: 11792960]

43. Vriesema JL, Aben KK, Witjes JA, Kiemeney LA, Schalken JA. Superficial and metachronous invasive bladder carcinomas are clonally related. Int J Cancer. 2001; 93:699-702. [PubMed: 11477581]

44. Rinkevich Y, Lindau P, Ueno H, Longaker MT, Weissman IL. Germ-layer and lineage-restricted stem/progenitors regenerate the mouse digit tip. Nature. 2011; 476:409-413. [PubMed: 21866153]

45. Montironi R, Mazzucchelli R, Lopez-Beltran A, Cheng L, Scarpelli M. Mechanisms of disease: high-grade prostatic intraepithelial neoplasia and other proposed preneoplastic lesions in the prostate. Nature clinical practice. Urology. 2007; 4:321-332.

46. Ayala AG, Ro JY. Prostatic intraepithelial neoplasia: recent advances. Arch Pathol Lab Med. 2007; 131:1257-1266. [PubMed: 17683188]

47. Scarlett CJ, Salisbury EL, Biankin AV, Kench J. Precursor lesions in pancreatic cancer: morphological and molecular pathology. Pathology. 2011; 43:183-200. [PubMed: 21436628]

48. Maitra A, Fukushima N, Takaori K, Hruban RH. Precursors to invasive pancreatic cancer. Adv Anat Pathol. 2005; 12:81-91. [PubMed: 15731576]

49. Allred DC. Ductal carcinoma in situ: terminology, classification, and natural history. J Natl Cancer Inst Monogr. 2010; 2010:134-138. [PubMed: 20956817]

50. Fearon ER, Vogelstein B. A genetic model for colorectal tumorigenesis. Cell. 1990; 61:759-767. [PubMed: 2188735]

51. Hoglund M. Bladder cancer, a two phased disease? Semin Cancer Biol. 2007; 17:225-232. [PubMed: 16574430]

52. Cheng L, et al. Precise microdissection of human bladder carcinomas reveals divergent tumor subclones in the same tumor. Cancer. 2002; 94:104-110. [PubMed: 11815965]

53. Slaughter DP, Southwick HW, Smejkal W. Field cancerization in oral stratified squamous epithelium; clinical implications of multicentric origin. Cancer. 1953; 6:963-968. [PubMed: 13094644]

54. Forsti A, Louhelainen J, Soderberg M, Wijkstrom H, Hemminki K. Loss of heterozygosity in tumour-adjacent normal tissue of breast and bladder cancer. European journal of cancer. 2001; 37:1372-1380. [PubMed: 11435067]

55. Prevo LJ, Sanchez CA, Galipeau PC, Reid BJ. p53-mutant clones and field effects in Barrett's esophagus. Cancer research. 1999; 59:4784-4787. [PubMed: 10519384] 
a

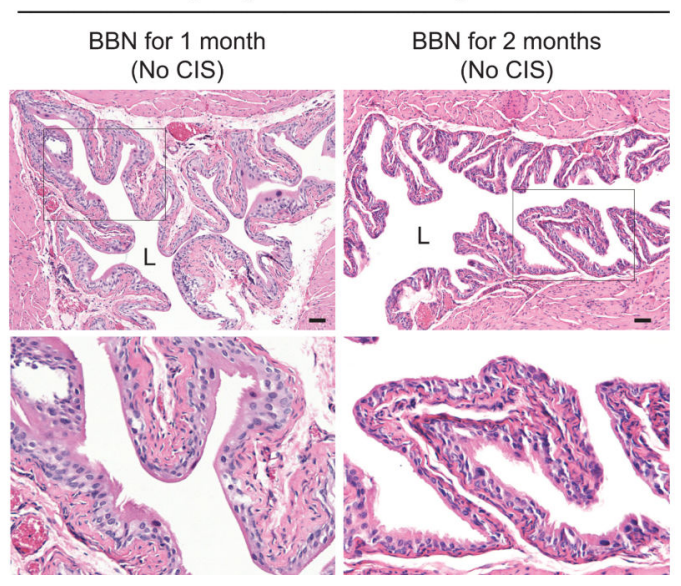

b

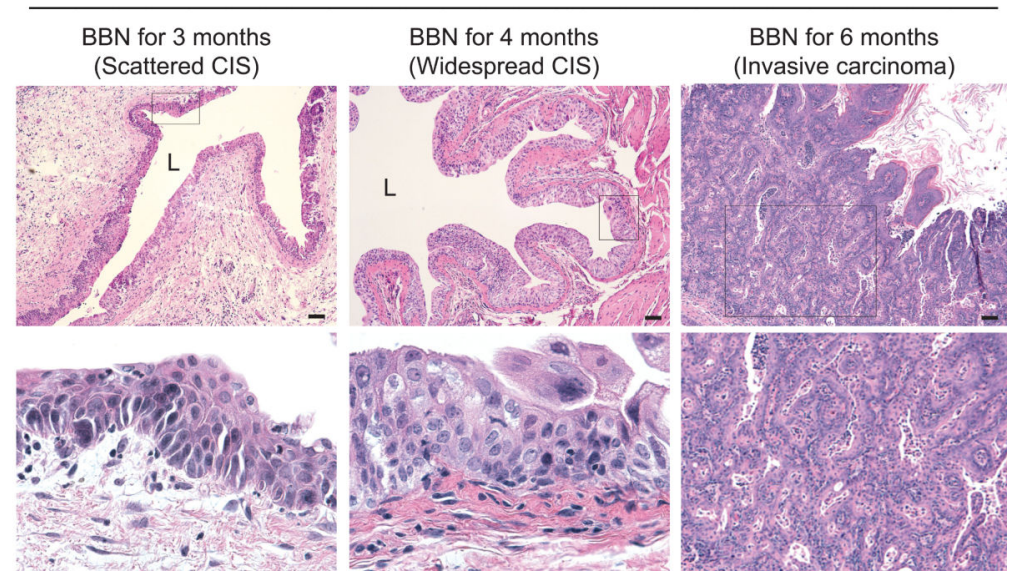

Figure 1. Histopathology of murine nitrosamine-induced bladder carcinoma mimics progression of human urothelial carcinoma in situ

(a,b) Histopathological analysis (H\&E staining) of early (a) and late (b) stages of BBNinduced bladder carcinogenesis (see also Supplementary Table 1). Lower panels show magnified views of the boxed regions in upper panels. Note the appearance, beginning at 3 months of BBN exposure, of histologic abnormalities, including nuclear atypia, crowding, and architectural disarray histologically identical to human carcinoma in situ (CIS), and leading to invasive carcinoma by six months of BBN exposure. L, bladder lumen. Scale

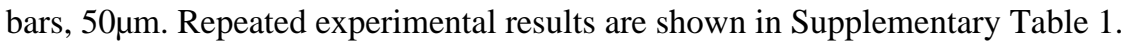


a BBN for 4 months; TM at 0 month

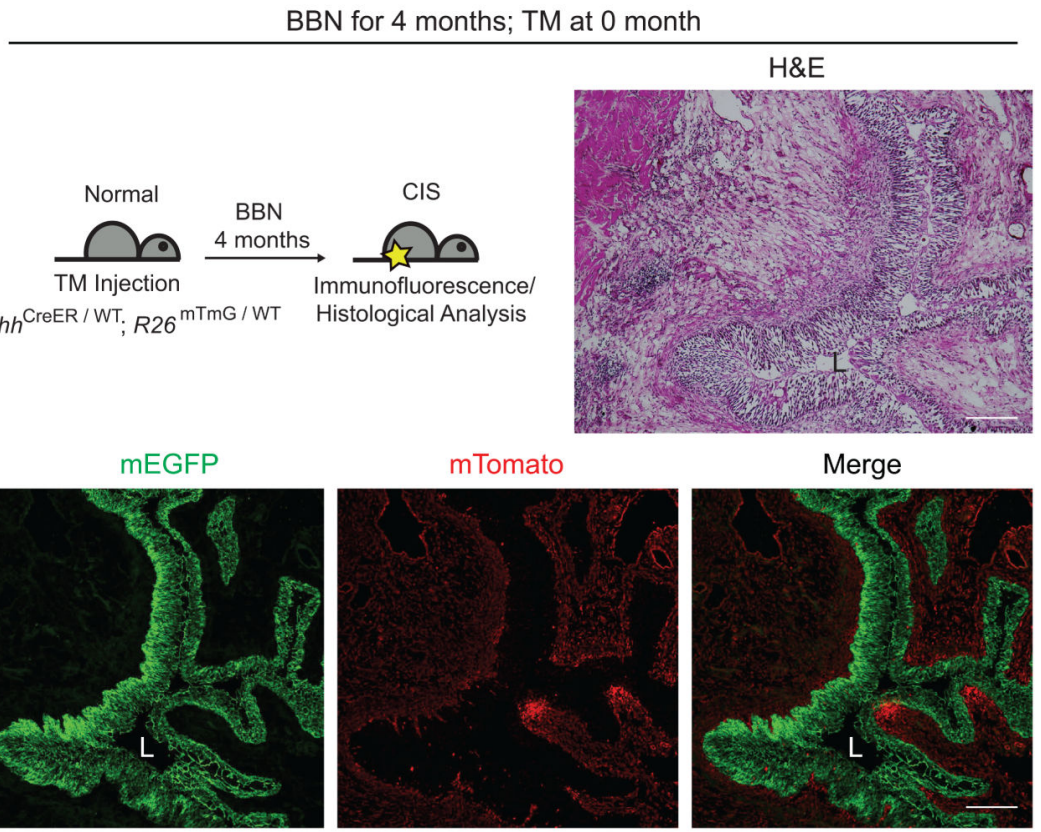

b BBN for 6 months; TM at 0 month

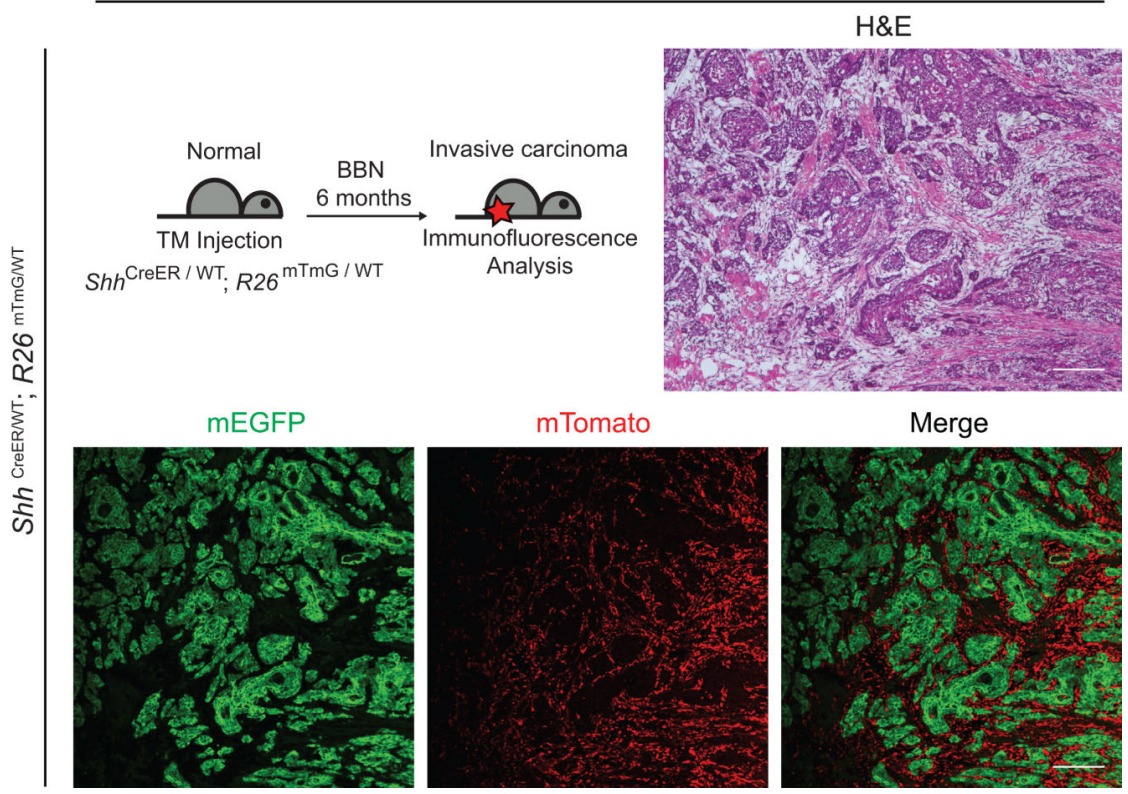

Figure 2. Shh-expression marks basal stem cells that give rise to CIS and invasive bladder carcinoma

Schematic diagrams (top left panels) show the experimental strategies for marking Shhexpressing cells and their progeny prior to BBN induction of CIS (a) or invasive carcinoma (b). Sh$h^{\mathrm{CreER}}, R 26^{\mathrm{mTmG}}$ mice injected with TM on three consecutive days were treated with $\mathrm{BBN}$ for four months to induce CIS lesions (a) or six months to induce bladder tumors (b), followed by histological analysis (H\&E) or analysis of $\mathrm{mG} / \mathrm{mT}$ expression. All tumors and CIS lesions are marked by expression of $\mathrm{mG}$, indicating that invasive carcinoma and CIS 
originate from Shh-expressing basal cells, not intermediate or lumenal cells. L, bladder lumen. Repeated experimental results are shown in Supplementary Figure 3. Scale bars, $50 \mu \mathrm{m}$. 
a

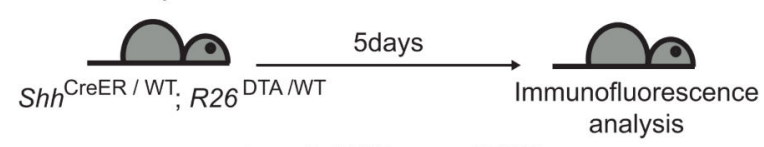

Shh CreER/WT; R26 DTAWT

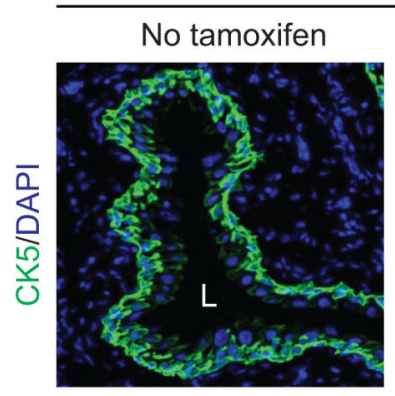

C

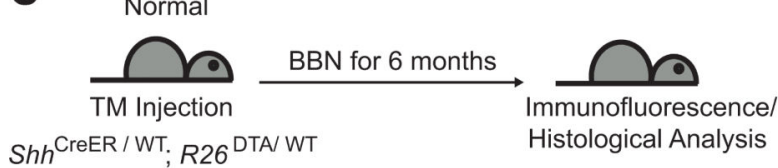

Shh CreER/WT; R26 DTAWT

(BBN for 6 months; TM at 0 month)
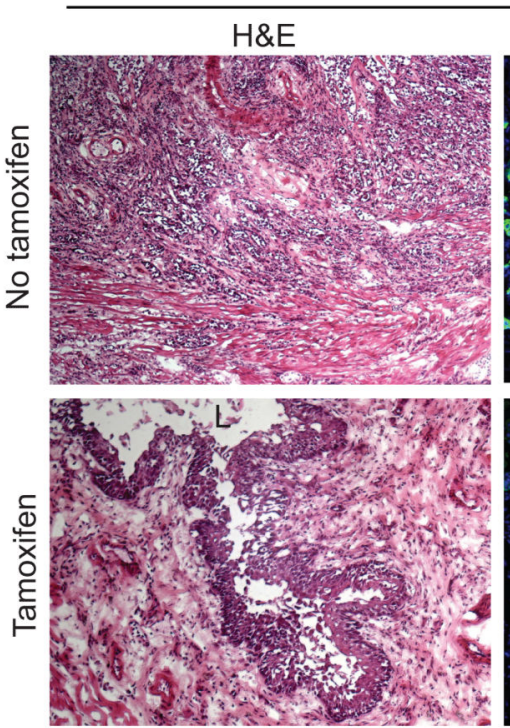

b
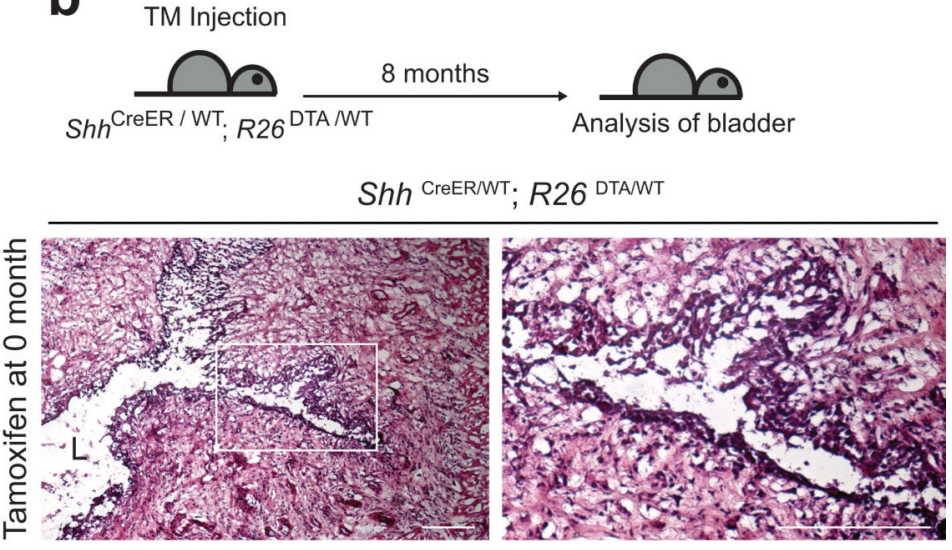

d

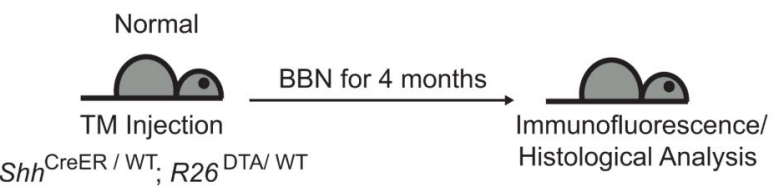

Shh CreER/WT; R26 DTAWT

(BBN for 4 months; TM at 0 month)

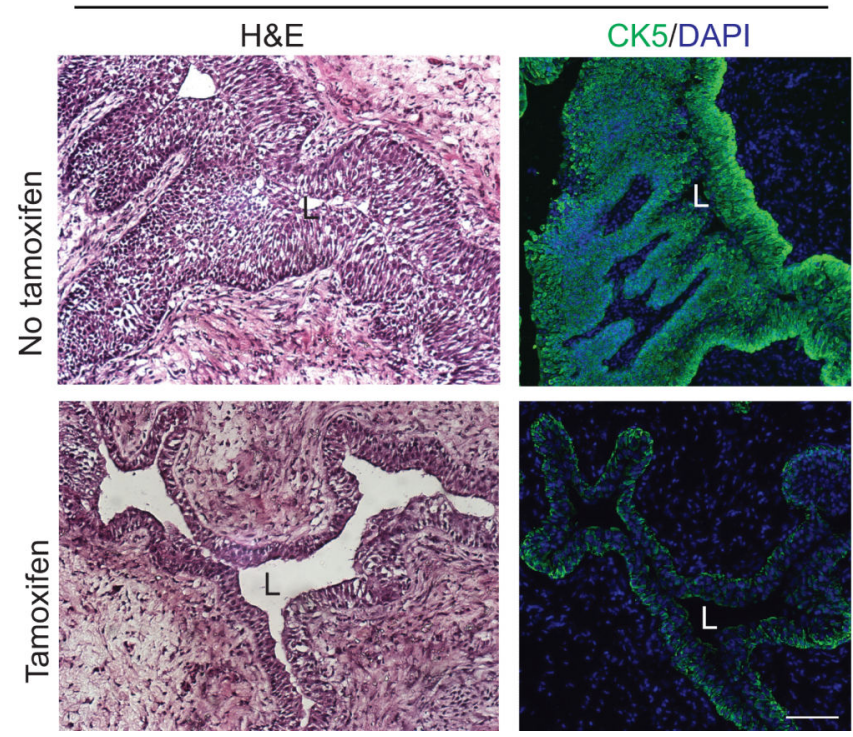

Figure 3. Ablation of $S h h$-expressing basal stem cells confers resistance to nitrosamine-induced formation of invasive bladder carcinoma

(a) TM was injected into $S h h^{\mathrm{CreER}} ; R 26^{\mathrm{DTA}}$ mice on five consecutive days. Five days after the last TM injection, bladders were analyzed by immunostaining. Sections from the bladders of control vehicle-injected or TM-injected mice (left and right panels, respectively) were stained for CK5 (green). Note that TM treatment effectively ablates basal epithelial cells in the $S h h^{\mathrm{CreER}} ; R 26^{\mathrm{DTA}}$ mouse bladder. (b) $S h h^{\mathrm{CreER}} ; R 26^{\mathrm{DTA}}$ mice were injected with TM on five consecutive days to ablate $S h h$-expressing basal cells and were maintained for 8 months without BBN exposure. Histology of the bladder from a mouse 8 months after 
TM injection shows the failure of maintenance of normal bladder epithelium, resulting from loss of stem cells. Right panel shows enlarged view of the boxed region in left panel. (c, d) TM was injected into $S h h^{\mathrm{CreER}} ; R 26^{\mathrm{DTA}}$ mice on five consecutive days to ablate $S h h_{\text {- }}$ expressing basal cells, and mice were exposed to BBN for 6 (c) or 4 (d) months. Bladder tissues were analyzed by H\&E staining (left panels) and immunostaining for CK5 (green, right panels). Upper panels show bladders from vehicle controls (no TM). L, bladder lumen. Repeated experimental results for (c) are shown in Supplementary Figure 4. Scale bars, $50 \mu \mathrm{m}$. 


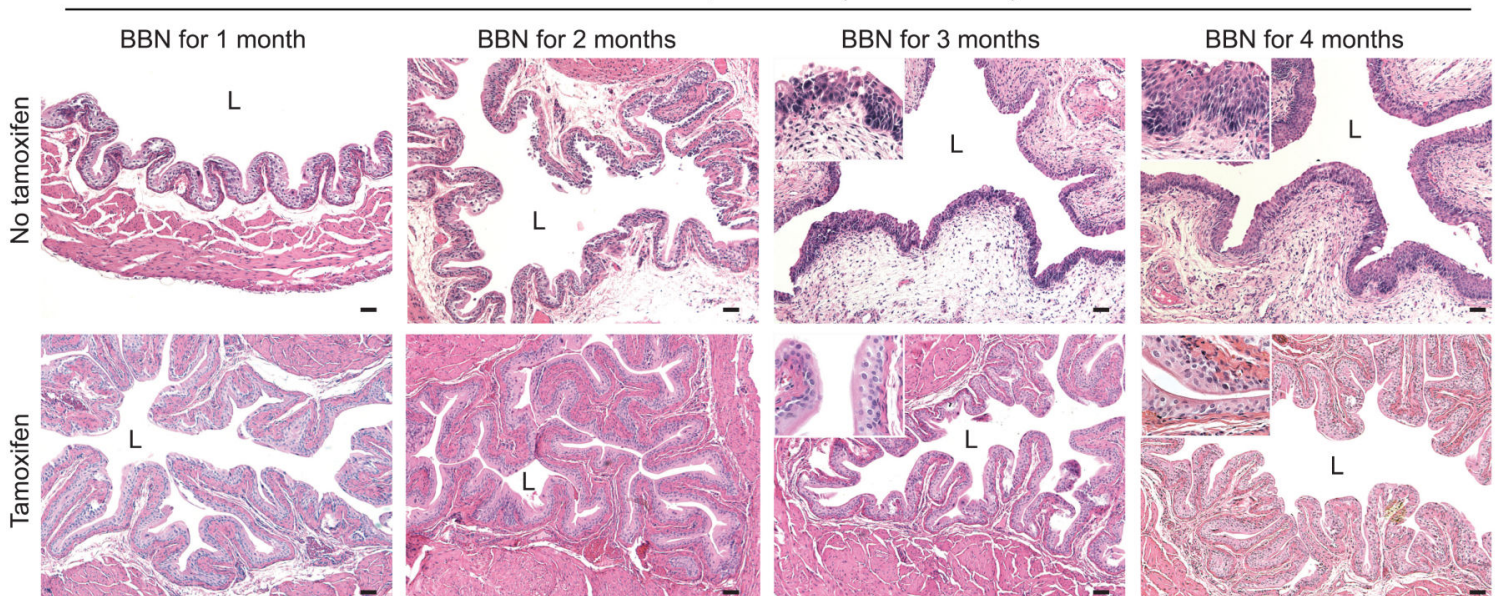

b

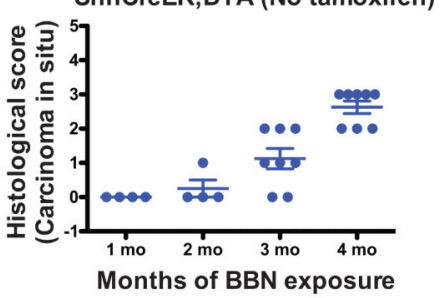

ShhCreER;DTA (Tamoxifen)

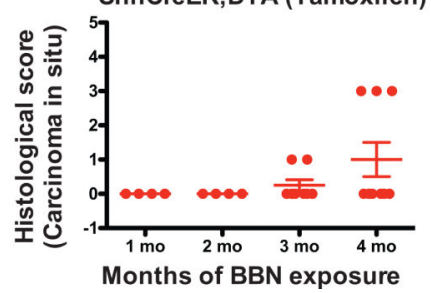

C

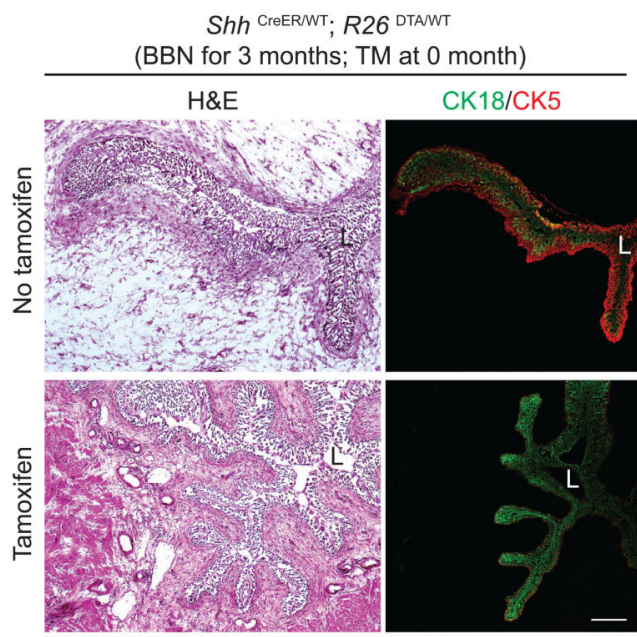

d

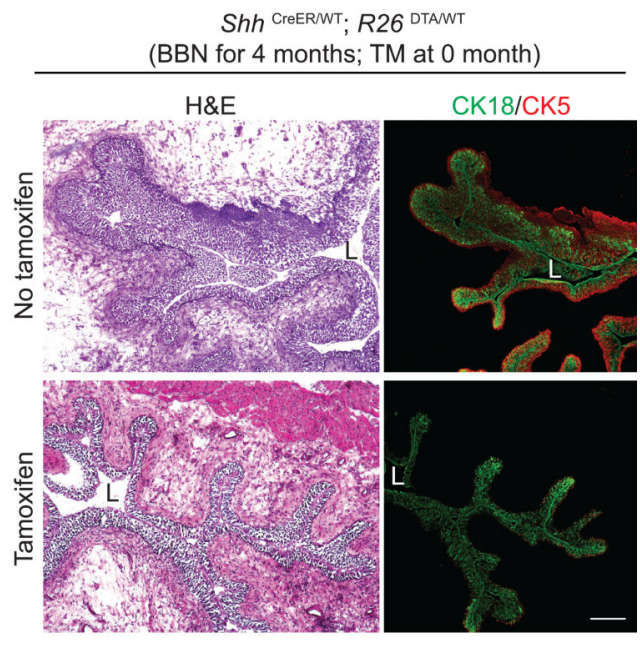

Figure 4. Ablation of $S h h$-expressing basal stem cells reduces CIS during nitrosamine-induced carcinogenesis while preserving urothelial architecture

(a) Histopathological analysis (H\&E) of TM-injected $S h h^{\mathrm{CreER}} ; R 26^{\mathrm{DTA}}$ mice after $1,2,3$, and 4 months of BBN exposure. Repeated experimental results are shown in Supplementary Table 2,3. (b) Histopathological evaluation of CIS in bladders from $S h h^{\mathrm{CreER}} ; R 26^{\mathrm{DTA}}$ mice (Supplementary Table 2, 3). Scores from 0-3 are based on extent of CIS within urothelium $(0$, none; $1,<10 \% ; 2,10-30 \% ; 3,>30 \%)$. No invasive carcinoma, and little or no CIS was induced by BBN exposure in animals with ablated stem cells. $n=4$ ( 1 month), $n=4$ (2 months), $\mathrm{n}=8$ (3 months), $\mathrm{n}=8$ (4months) for vehicle-treated $S h h^{\text {CreER}}$; $R 26^{\text {DTA }}$ mice; $\mathrm{n}=4$ (1 month), $\mathrm{n}=4$ ( 2 months), $\mathrm{n}=8$ ( 3 months), $\mathrm{n}=9$ (4months) for tamoxifen-treated $S h h^{\mathrm{CreER}}$; $R 26^{\mathrm{DTA}}$ mice. Data are presented as mean \pm s.e.m (c,d) $S h h^{\mathrm{CreER}} ; R 26^{\mathrm{DTA}}$ mice were injected with TM on five consecutive days to ablate $S h$-expressing basal cells and exposed to BBN for 3 (c) and 4 (d) months. Sections from the bladders of control vehicle-injected or TM-injected mice (top and bottom panels, respectively) were stained for the luminal and basal markers, CK18 and CK5 (green and red, respectively). Note that lumenal cells are well-preserved at intermediate stages of BBN exposure in stem cell ablated animals. L, bladder lumen. Scale bars, $50 \mu \mathrm{m}$. 
a

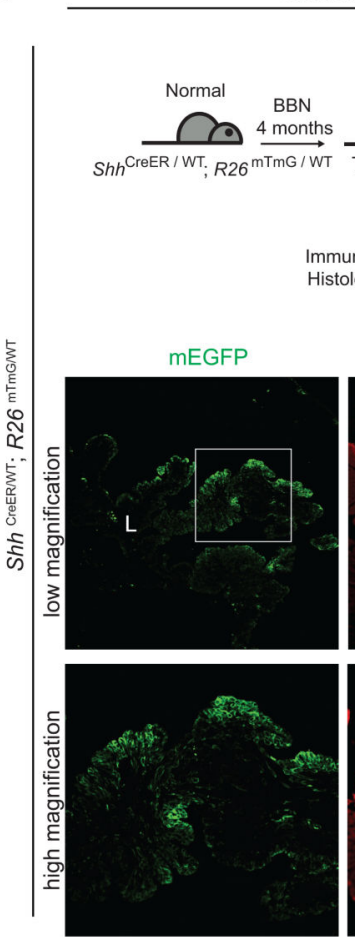

b

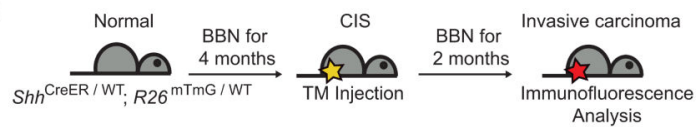

C

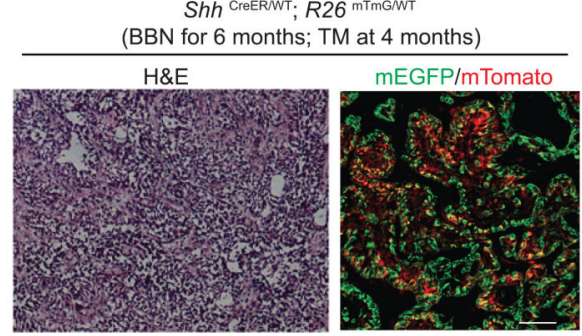

d

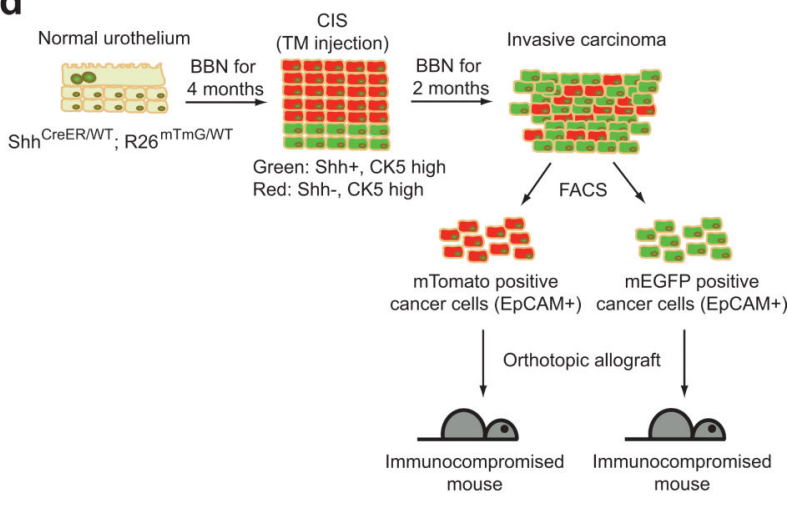

e

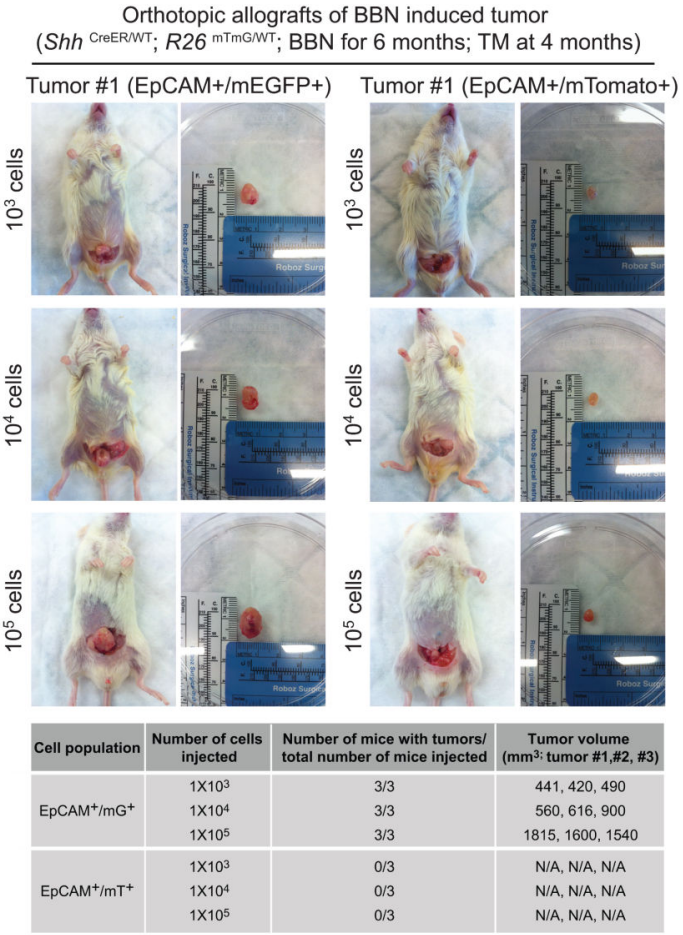

Figure 5. Shh-positive and -negative cells in the CIS lesion contribute to invasive carcinoma, but tumor-propagating cells derive exclusively from $S h h$-positive cells

(a) Experimental scheme (top left panel) to label Shh-expressing cells in the CIS lesion. Following 4 months of BBN exposure to induce CIS, Shh ${ }^{\mathrm{CreER}} ; R 26^{\mathrm{mTmG}}$ mice were injected with TM on three consecutive days to label $S h h$-expressing cells prior to sacrifice. Bladder tissues were analyzed by H\&E staining (top right panel) or by immunostaining for $\mathrm{mG}$ and CK5 (green and red, respectively). Lower panels show magnified views of the regions highlighted by white boxes in panels immediately above. (b) Experimental scheme for marking of Shh-positive and -negative cells in CIS lesions, and to track them into carcinoma formation. (c) $S h h^{\mathrm{CreER}} ; R 26^{\mathrm{mTmG}}$ mice exposed to BBN for 4 months and injected with TM on three consecutive days, were subsequently exposed to BBN for two more months. Invasive carcinomas from these animals were analyzed by $\mathrm{H} \& \mathrm{E}$ staining (left panel) or for expression of $\mathrm{mG}$ or $\mathrm{mT}$, which respectively marks cells that expressed (green) 
or did not express (red) Shh at the time of TM injection. (d) Experimental scheme to determine tumor-propagating ability of carcinoma cells. mG/EpCAM-positive and mT/ EpCAM-positive cells from invasive carcinomas generated as described in (b) were isolated by FACS and transplanted intramurally into the dome of the bladder. (e) Orthotopic transplantation with serial dilutions of $\mathrm{mG} / \mathrm{EpCAM}$-positive and mT/EpCAM-positive cells from a single tumor. Results of transplantations from three different tumors, summarized below, show that only $S h$-expressing cells in the CIS lesion will subsequently become tumor-propagating cells in transplantation experiments. L, bladder lumen. Repeated experimental results for (a) and (e) are shown in Supplementary Figure 5a and 5d, respectively. Scale bars, $50 \mu \mathrm{m}$. 


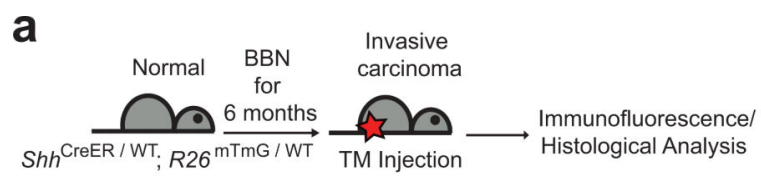

b

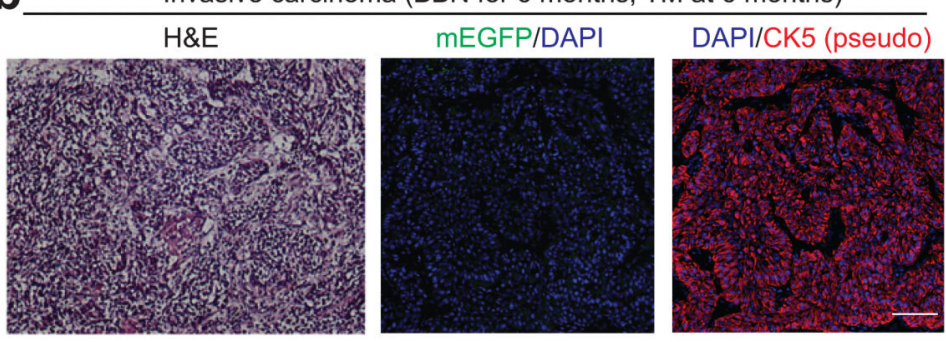

d

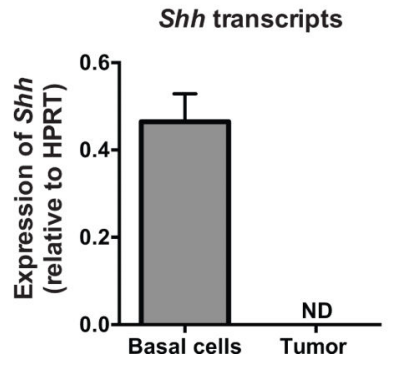

C
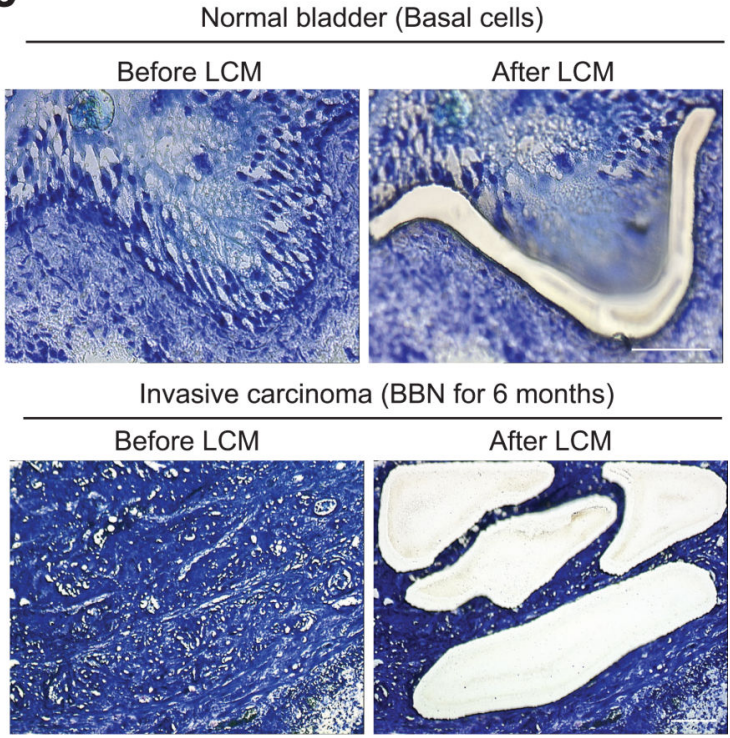

Figure 6. Shh expression is lost in invasive carcinoma of murine bladder

(a) Experimental scheme for marking of $S h h$-expressing cells in invasive carcinoma induced by 6 months of BBN exposure. (b) $S h h^{\mathrm{CreER}} ; R 26^{\mathrm{mTmG}}$ mice exposed to BBN for 6 months were injected with TM on three consecutive days to label $S h h$-expressing cells prior to sacrifice, and the bladder carcinoma was analyzed by H\&E staining (left panel) or by immunostaining for $\mathrm{mG}$ and CK5 (green and red, respectively, in middle and right panels), with DAPI staining to visualize nuclei. Note the lack of $\mathrm{mG}$ expression in the carcinoma, indicating the absence of $S h h$ expression, whereas CK5 expression is seen in all cancer cells.

(c) Laser capture microdissection (LCM) of normal basal cell layer (upper panels) in untreated bladder and of carcinoma cells within tumor (lower panels). Nine tumor areas were assessed ( 3 different tumor areas from 3 distinct tumors) and representative images are shown here (area \#1 from tumor \#1). Other areas from 3 distinct tumors (areas \#2-3 in tumor \#1; areas \#1-3 for tumor \#2; areas \#1-3 from tumor \#3) are shown in Supplementary Figure 7a. (d) Shh mRNA is detected in cells microdissected from normal basal cells but absent from carcinoma cells. ND, not detected. Data are presented as mean \pm s.e.m from 3 technical replicates; 9 tumor areas were assessed (3 different tumor areas from 3 distinct tumors). Scale bars, $50 \mu \mathrm{m}$. 
a

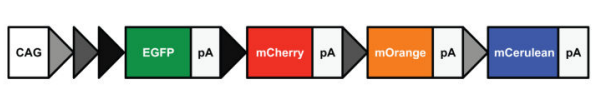

b

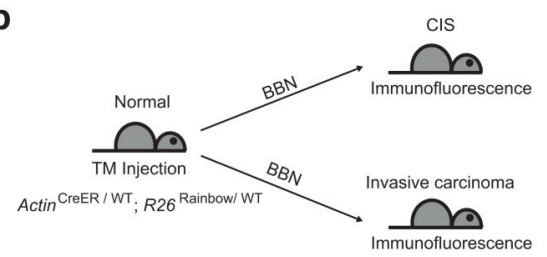

C
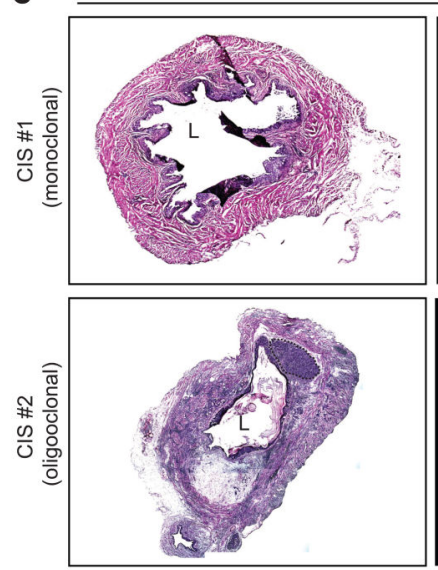

Actin CreERNT; R26 Rainbow'WT (TM at 0 month)
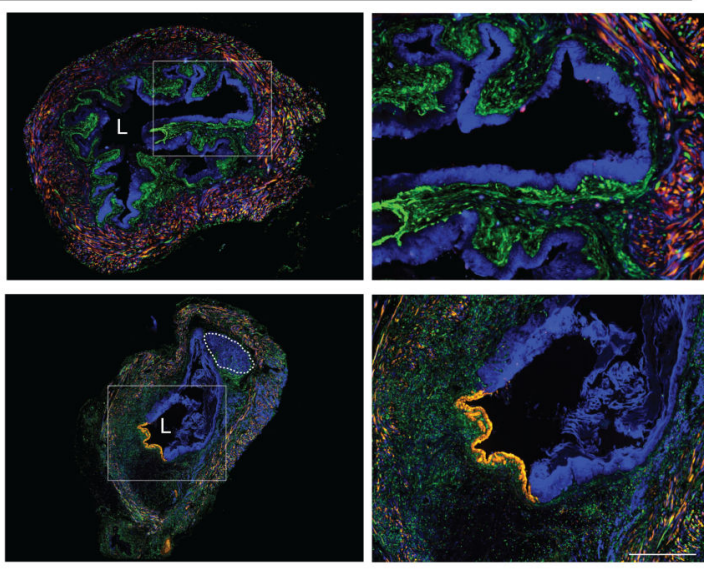

d

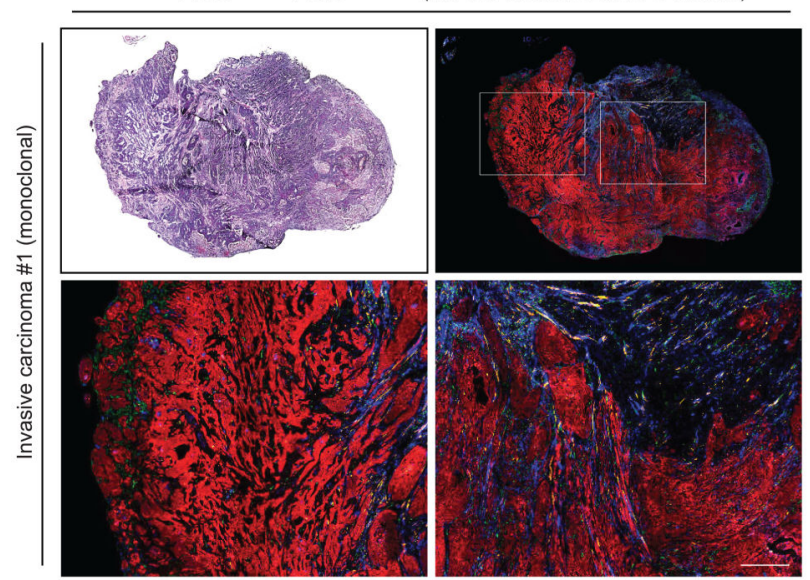

e

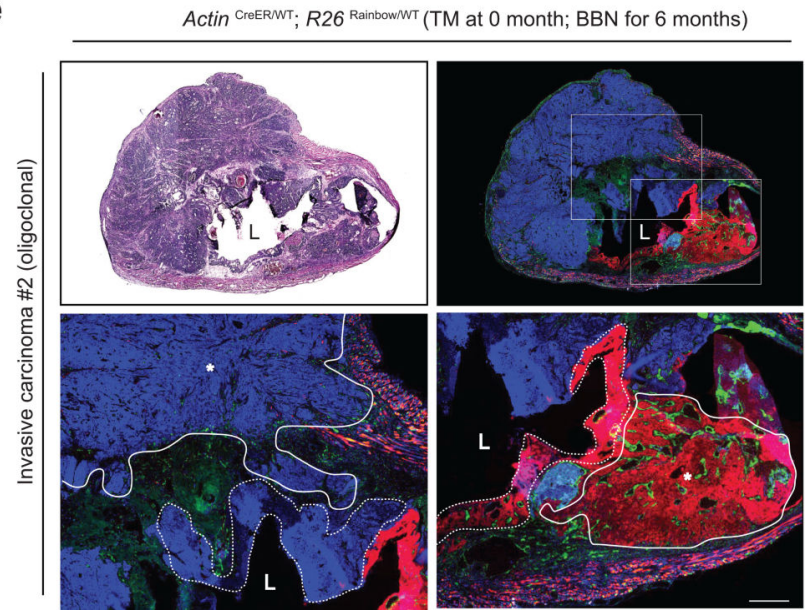

Figure 7. Four-color marking reveals monoclonal and oligoclonal urothelial colonization and carcinoma formation upon nitrosamine exposure

(a) Schematic diagram of the Rainbow allele. By virtue of three different lox sites (loxP, loxN and lox2272), individual cells express either EGFP (before Cre-mediated recombinmation) or mCherry, mOrange, or mCerulean (after Cre-mediated recombination). (b) Experimental scheme to investigate clonal relationships during bladder carcinogenesis. A low dose of TM injected into Actin ${ }^{\text {CreER; }}$ R2 $6^{\text {Rainbow }}$ mice stochastically labeled bladder cells with one of four fluorescence colors, and these animals then were exposed to BBN until they developed CIS (c) or invasive carcinoma (d,e). (c) Bladders from TM-injected Actin $^{\text {CreER; }}$ R26 $6^{\text {Rainbow }}$ mice exposed to BBN for 4 months (CIS \#1) or 5 months (CIS \#2) and analyzed by H\&E staining (left panels) or for four-color fluorescence. Right panels show magnified views of the regions highlighted by white boxes in middle panels. CIS lesions covering the entire urothelium arise from a single (\#1, monoclonal) or two cells (\#2, oligoclonal). A small carcinoma arising within the blue-marked CIS \#2 is outlined by a dotted line. (d,e) Bladders from TM-injected Actin ${ }^{\mathrm{CreER}}$; $26^{\text {Rainbow }}$ mice exposed to BBN for 6 months were analyzed by H\&E staining (top left panels) or for four color fluorescence (top right panels). Bottom panels show magnified views of the regions highlighted by white boxes in top right panels. Carcinomas within a single bladder arise from one (d, monoclonal) or several (e, oligoclonal) cells, respectively. In (e), tumors are outlined by 
solid lines with asterisks and nearby CIS regions are outlined by dotted lines. L, bladder lumen. Scale bars, $50 \mu \mathrm{m}$. 
Normal urothelium

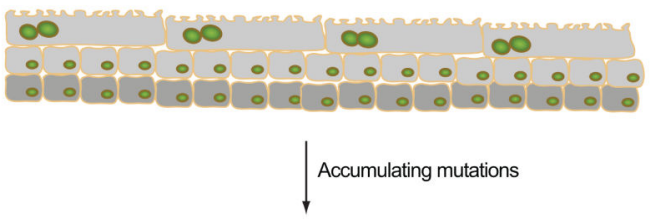

Pre CIS (No histological changes)

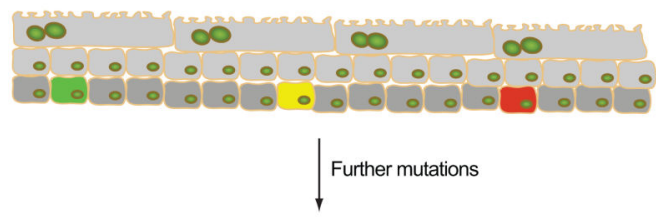

Scattered CIS

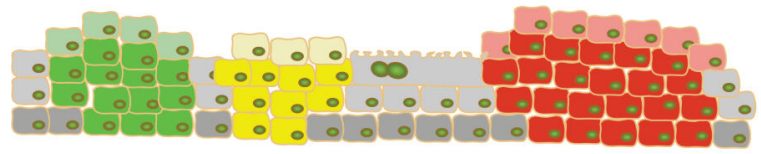

Invasive carcinoma

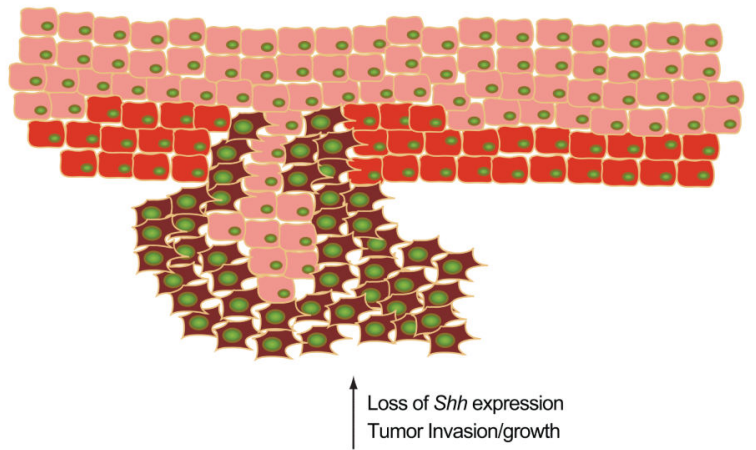

Widespread CIS

Clonal expansion

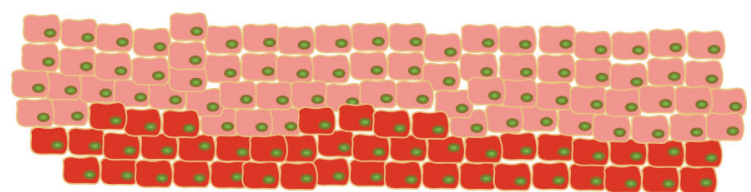

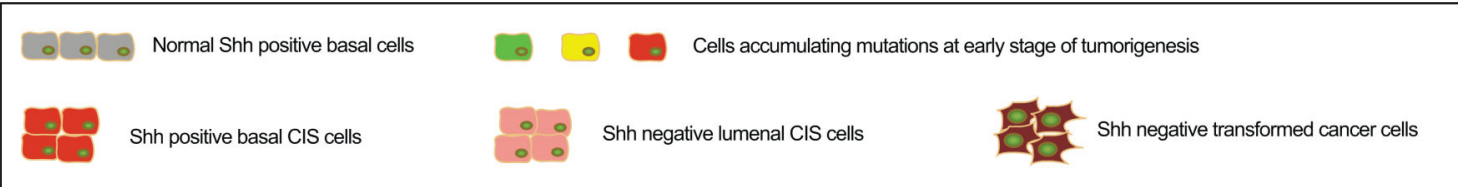

Figure 8. Model for progression of nitrosamine-induced bladder carcinogenesis BBN-induced invasive carcinoma of the mouse bladder arises from basal stem cells that express Shh and CK5. Normal basal cells accumulate mutations at early stages of carcinogenesis and initiate clonal expansions to form intermediate CIS lesions, as indicated by green, yellow, and red colors. During this process, one or two clones become dominant and expand to repopulate the entire urothelium, generating mono/oligo clonal CIS lesions. CIS basal cells in one of these lesions then lose expression of Shh upon establishment of invasive carcinoma. 